\title{
The Genetic Architecture of Disease Resistance in Maize: A Synthesis of Published Studies
}

\author{
Randall J. Wisser, Peter J. Balint-Kurti, and Rebecca J. Nelson
}

First author: Department of Plant Breeding and Genetics, Institute for Genomic Diversity, 160 Biotechnology Building, Cornell University, Ithaca, NY 14853; second author: U.S. Department of Agriculture-Agricultural Research Service, 3418 Gardner Hall, Department of Plant Pathology, North Carolina State University, Raleigh 27695; and third author: Department of Plant Pathology, 321 Plant Science, Cornell University, Ithaca, NY 14853.

Accepted for publication 13 September 2005.

\begin{abstract}
Wisser, R. J., Balint-Kurti, P. J., and Nelson, R. J. 2006. The genetic architecture of disease resistance in maize: A synthesis of published studies. Phytopathology 96:120-129.

Fifty publications on the mapping of maize disease resistance loci were synthesized. These papers reported the locations of 437 quantitative trait loci (QTL) for disease (dQTL), 17 resistance genes (R-genes), and 25 Rgene analogs. A set of rules was devised to enable the placement of these loci on a single consensus map, permitting analysis of the distribution of resistance loci identified across a variety of maize germplasm for a num-

distributed over all 10 chromosomes and covered $89 \%$ of the genetic map to which the data were anchored. Visual inspection indicated the presence of clusters of dQTL for multiple diseases. Clustering of dQTL was supported by statistical tests that took into account genome-wide variations in gene density. Several novel clusters of resistance loci were identified. Evidence was also found for the association of dQTL with maturityrelated QTL. It was evident from the distinct dQTL distributions for the different diseases that certain breeding schemes may be more suitable for certain diseases. This review provides an up-to-date synthesis of reports on the locations of resistance loci in maize.
\end{abstract} ber of different diseases. The confidence intervals of the dQTL were
In many economically important plant pathosystems, disease is controlled by breeding for genetic resistance in the host plant. Plant pathologists and breeders recognize two general types of resistance: qualitative and quantitative. Qualitative resistance typically confers a high level of resistance, is usually race-specific, and is based on single dominant or recessive genes. In contrast, quantitative resistance in plants is typically partial and race-nonspecific in phenotype, oligogenic or polygenic in inheritance and is conditioned by additive or partially dominant genes. Although it is easier to work with qualitative resistance in crop genetic studies and in breeding, quantitative resistance is often the more useful in an agronomic context, due to its generally higher durability and broader specificity $(46,55)$. In maize, the majority of disease resistance deployed in elite varieties in the field is quantitative in nature.

Genes conditioning qualitative resistance, often termed Rgenes, can be mapped using Mendelian genetics. R-genes have been cloned in many systems and their modes of action and signal transduction pathways defined $(28,32,64)$. Cloning genes conditioning quantitative resistance is much more challenging because of their modest phenotypic effects. Since the first mapping study on quantitative trait loci (QTL) in a crop plant was published in 1988 (56), a substantial number of studies have been conducted to map QTL for resistance to plant diseases (80).

The disease QTL (dQTL) mapping studies conducted in maize thus far have provided information on the genetic architecture of disease resistance, including the number, location, and action of chromosomal segments conditioning the trait. In each primary study, the chromosomal segments associated with quantitative resistance were identified with the aid of molecular markers (40,

Corresponding author: R. J. Nelson; E-mail address: rjn7@ cornell.edu

DOI: $10.1094 /$ PHYTO-96-0120

This article is in the public domain and not copyrightable. It may be freely reprinted with customary crediting of the source. The American Phytopathological Society, 2006.
62,73 ) and the allelic contrasts in one or a few biparental crosses were analyzed in one or a few environments. Each study thus sheds light on the genetic architecture of the trait in the specific populations under study. To achieve a broader picture of the genetic architecture of disease resistance in the species, however, the data from multiple studies must be synthesized.

The purpose of this paper is to integrate the results presented in 50 publications on qualitative and quantitative resistance to fungal, oomycete, bacterial, and viral pathogens and R-gene analogs (RGAs) in maize. Based on this synthesis, we address the following questions about the genetic architecture of disease resistance in a crop of global importance. How many dQTL have been declared in the published literature? What proportion of the maize genome has been associated with these QTL? Is there evidence for a nonrandom distribution of dQTL, and if so, can dQTL "hotspots" in the maize genome be identified? Are qualitative and quantitative disease resistance loci associated? Do certain genomic regions condition multiple disease resistance, i.e., resistance to different pathogens? And to what extent do dQTL colocalize with QTL associated with plant development (e.g., days to flowering)?

\section{PRIOR STUDIES}

Previous reviews of plant quantitative disease resistance. Several papers published over the last decade have examined the genomic organization of disease resistance genes in maize and other plant species. In 1995, McMullen and Simcox (51) reviewed the genomic organization of disease and insect resistance genes in maize. The maize genome has been divided into 100 "bins" of approximately 20 centimorgans (cM) each $(18,24)$, which are designated by the chromosome number and a two-digit decimal (e.g., 1.01, 1.02, etc.). They summarized the positions of reported resistance loci according to those bins, and found evidence for a nonrandom distribution of resistance loci based on a 
synthesis of results reported in 16 papers documenting 34 dQTL and 19 major genes. Closely linked resistance gene clusters were identified in bins 3.04 and 6.01 and more diffuse clusters were seen elsewhere in the genome. Welz and Geiger (74) summarized the results of mapping of resistance to the fungal disease northern corn leaf blight in three different maize populations. The three populations shared three dQTL regions in common on chromosomes 3,5 , and 8 . These regions were also the sites of dQTL and

TABLE 1. Published studies used to analyze the location and clustering of disease resistance loci on maize chromosomes

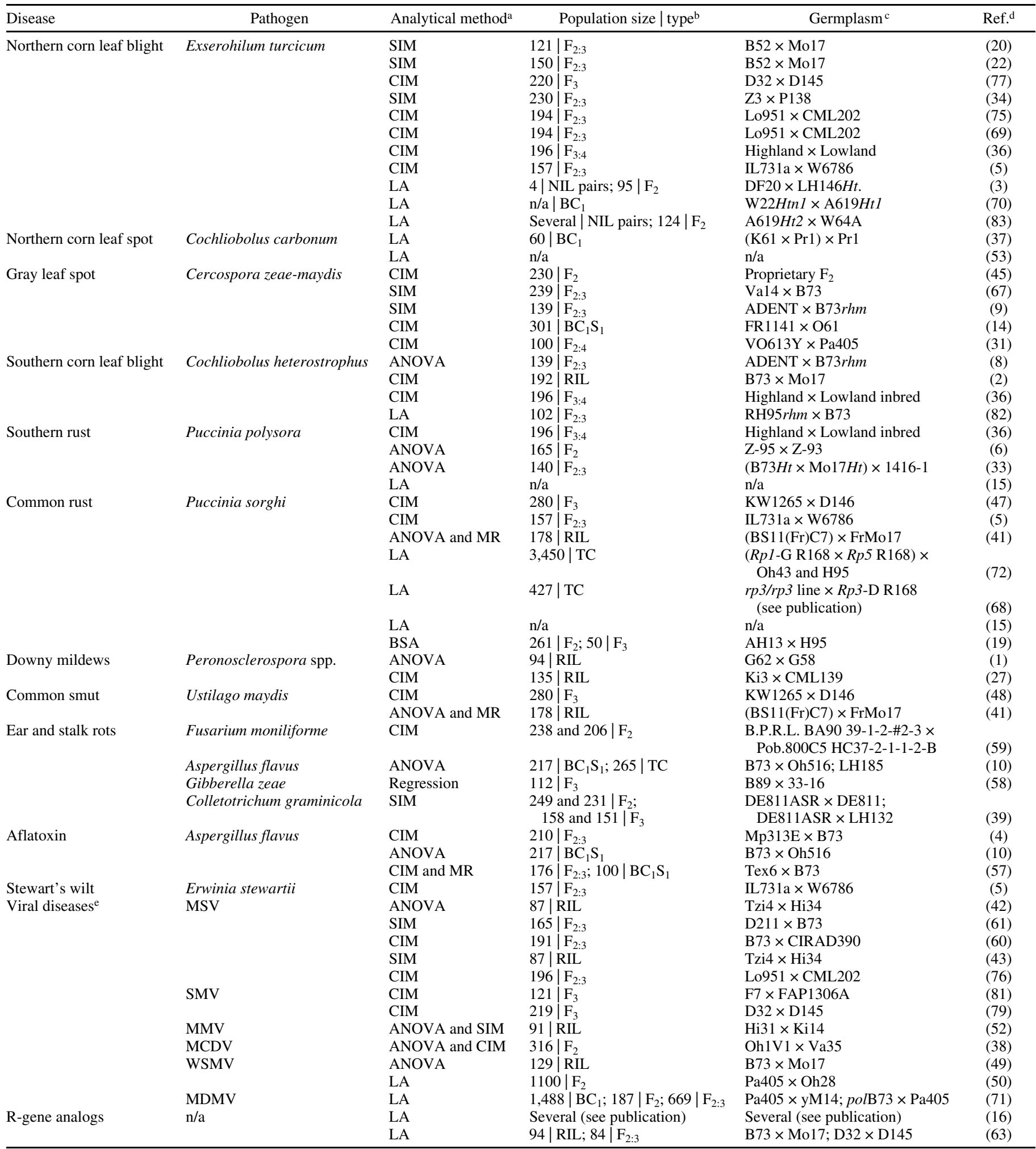

a Analytical method used to determine the locations of resistance loci. SIM, simple interval mapping; CIM, composite interval mapping; LA, linkage analysis; ANOVA, analysis of variance; MR, multiple regression; and BSA, bulked segregant analysis.

${ }^{b}$ The number of progeny and the type of population analyzed. NIL, near-isogenic line; RIL, recombinant inbred line; BC, backcross; and TC, testcross.

${ }^{c}$ The germplasm from which the population under study was derived.

${ }^{\mathrm{d}}$ The primary reference for the study.

e Viral diseases: MSV, Maize streak virus; SMV, Sugarcane mosaic virus; MMV, Maize mosaic virus; MCDV, Maize chlorotic dwarf virus; and WSMV, Wheat streak mosaic virus. 
major genes for resistance to several other fungal diseases and insect pests.

Gebhardt and Valkonen (26) summarized the organization of potato disease resistance loci and found evidence for clustering of both classes of genes; they suggested that R-gene homologues might in some cases condition quantitative resistance. Wisser et al. (78) exploited the burgeoning genomic information on the rice genome in their analysis of the genomic organization of disease resistance genes in rice. They reported evidence for clustering of dQTL and R-genes, and that the two classes of resistance loci were significantly associated with one another.

Disease QTL studies in maize. Table 1 lists the papers summarized in this review, comprising all published studies known to the authors (as of July 2005) reporting QTL or major genes for resistance to fungal, oomycete, bacterial, and viral diseases of maize, and RGAs. These 50 publications reported 57 studies (counting analyses of two diseases reported in a single publication as two studies) of resistance to 11 diseases or disease groups (counting ear and stalk rots, different downy mildews, and different viral diseases as three separate disease groups, respectively) and two studies of RGAs. In this set, 437 dQTL, 17 major genes, and 25 RGAs were reported.

\section{THE CONSENSUS MAP}

A consensus map of maize resistance loci. Several challenges were confronted in comparing the results of previous studies, largely because the studies were performed with many different segregating populations, using different sets of molecular markers and reporting their results in different ways. With recent advances in maize genomics, it is now possible to unite previous studies onto a single genetic framework to facilitate a synthesis of genetic map data. A consensus map of the previously published dQTL, Rgene, and RGA data was constructed by anchoring each of the loci onto the intermated B73 $\times$ Mo17 population genetic map (version IBM2 Neighbors [IBM2n], publicly available online from the Maize Genetics and Genomics Database [MaizeGDB]) via the names of reported maize bins and/or molecular markers defining each locus (Fig. 1).

We used the following rule set to produce the consensus map: (i) all resistance loci declared in each study were recorded without weighting by locus characteristics (e.g., the proportion of the variation they explained); (ii) "redundant" QTL (i.e., multiple QTL for the same disease identified over environments or for related phenotypic parameters, overlapping by more than $50 \%$, and

\section{Chromosome 1}

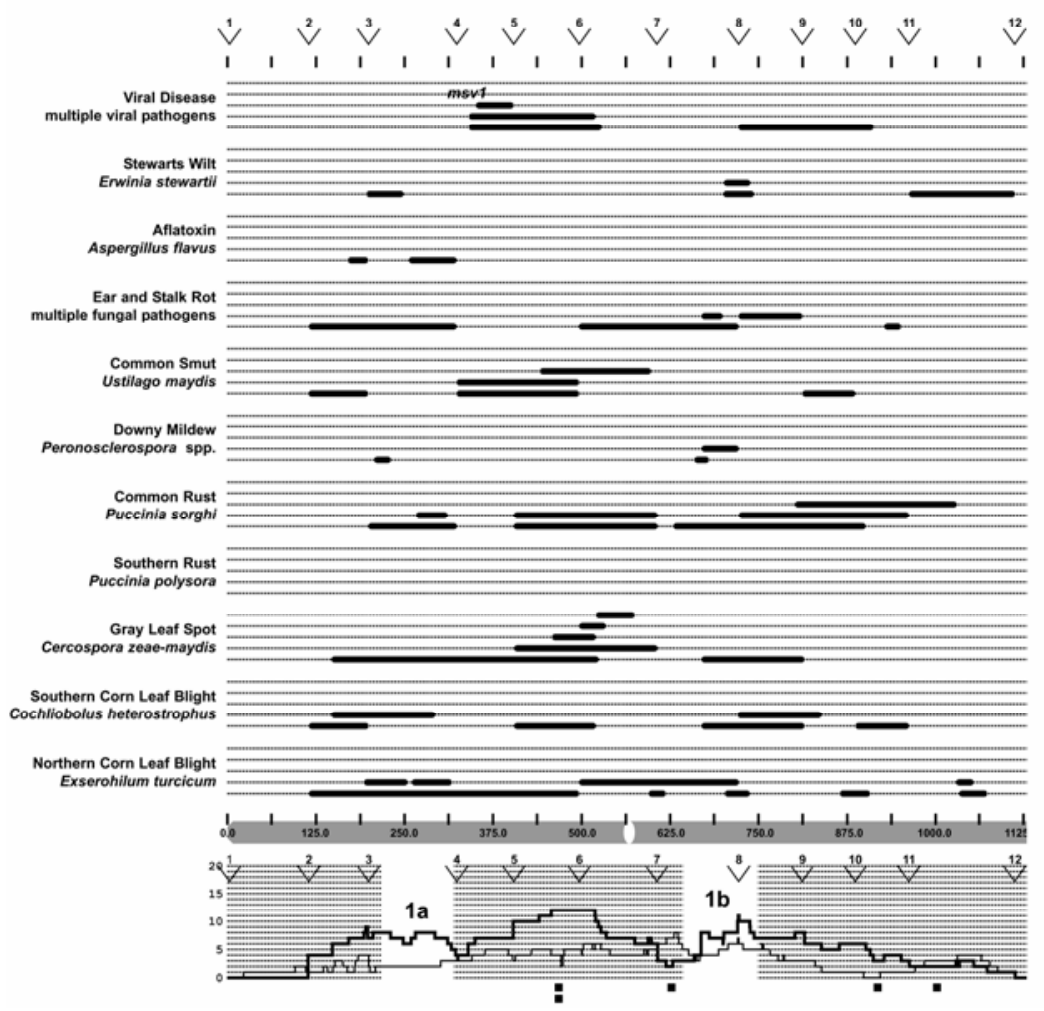

Chromosome 2

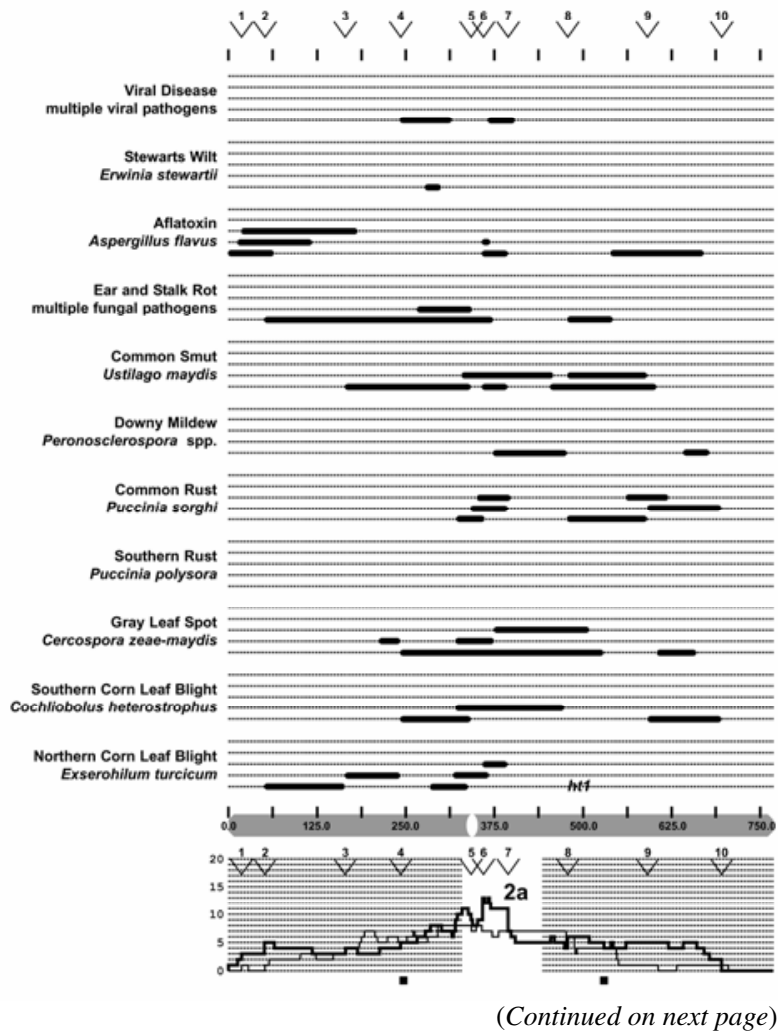

Fig. 1. Consensus map of resistance loci in maize. Each of the 10 maize chromosomes is portrayed with gray shading with the IBM2n centimorgan scale inside. Centromeres are represented by white ovals. The standard maize bin boundaries are indicated by arrowheads with a number indicating the start of a given bin. The zero bins are not indicated as they start at the beginning of each chromosome (e.g., chromosome 1 is composed of 13 bins: 1.00 to 1.12). The start position of bin 4.01 had been assigned a negative centimorgan value on the IBM2n map, so it occurs before the $0 \mathrm{cM}$ start position, and is therefore not shown. The disease quantitative trait loci (dQTL) (black bars) are shown above each chromosome, grouped across studies according to a specific disease or group of diseases. Disease QTL identified for multiple pathogens causing ear and stalk rot were grouped. Similarly, QTL for different oomycete pathogenic species (downy mildews) were grouped and viral dQTL were grouped. The causal agents for ear rot were Fusarium moniliforme, Aspergillus flavus, and Gibberella zeae; for stalk rot, Colletotrichum graminicola; for downy mildew: Peronosclerospora sorghi, P. heteropogoni, P. maydis, P. zeae, and P. philippinensis; and for viral diseases, High plains virus, Maize chlorotic dwarf virus, Maize dwarf mosaic virus, Maize mosaic virus, Maize streak virus, Sugarcane mosaic virus, and Wheat streak mosaic virus. The locations of R-gene loci are shown with dQTL for the diseases to which they have been reported to condition resistance to, and are indicated according to their locus names. The major genes $\mathrm{Hm} 1$ and $\mathrm{Hm} 2$, which confer resistance to northern corn leaf spot (37,53), are not shown because no QTL were reported. Once placed on the consensus map, they were located on chromosome 1 from 590 to $607 \mathrm{cM}$ and chromosome 9 from 254 to $259 \mathrm{cM}$, respectively. The locations of R-gene analogs are shown as black filled boxes at the very bottom of each chromosomal figure. Below each chromosome is a histogram summarizing the QTL frequency per centimorgan. The thicker line shows the frequency of dQTL and the thinner line maturity-related QTL. The frequency scale is to the left of the histogram. Genomic regions (A-bins) where the observed dQTL number exceeded the expected dQTL number based on gene density, by a factor of at least two, are indicated as white areas in each histogram. Numbers indicate the chromosome to which the cluster belongs and letters indicate different clusters on the same chromosome. 
associated with the same parental allele) were concatenated and recorded as single QTL; (iii) a 95\% confidence interval was constructed (17) for QTL defined by a single most significant molecular marker; (iv) QTL locations published according to the maize bins were recorded as intervals covering the entire bin area; and (v) markers not available on the IBM2n map were located either as a relative position between flanking markers on the IBM2n, inferred from their relative position between those same flanking markers reported in the study or on other maps available in MaizeGDB (an approach called the "homothetic function" [13]), or to a bin, in which case rule (iv) was applied.

Considering the rule set used in deriving the consensus map, several assumptions and potential caveats should be recognized. The approach assumes chromosomal homologies across the maize germplasm, such that the inferred locations on the IBM2n map preserve the locations reported in each study. Sequencing of common chromosomal segments across maize cultivars has revealed that a given locus may be nonallelic across different maize lines (i.e., have different gene or other sequence content $[7,23]$ ), so in certain cases this assumption might be violated. Almost all of the publications reported the chromosomes to which the declared resistance loci were located. For only five markers (defining three QTL) were discrepancies noted between the reported chromosome to which they belonged and the chromosome to which they were assigned on the IBM2n map.

Other caveats to this type of analysis relate to the evolution of QTL analysis. The QTL studies reviewed were reported over a span of 14 years. Standard experimental designs, map densities, and methodologies for declaring QTL have changed to some extent over the years, making comparisons across studies potentially subjective. Furthermore, no standard has been followed in declaring a QTL. For instance, the experiment-wise $P$ value thresholds were not always stated; those reported ranged from 0.01 to 0.10 .
A total of $437 \mathrm{dQTL}$ were declared across the studies, with an average of 6.4 per study and a range of 1 to 16 per study. This does not include the 17 studies in which only major genes were located. After accounting for redundancy, the total dQTL number was reduced to 319 . The confidence intervals of the dQTL were distributed over all 10 chromosomes and covered $89 \%$ of the genetic map.

The maize karyotype is ordered in generally decreasing physical size, and chromosome size is generally related to the estimated number of all maize genes. The number of dQTL per chromosome tended to decrease with chromosome size and the number of genes per chromosome. For example, there were 51 dQTL on the largest chromosome (chromosome 1) and 17 on the smallest chromosome (chromosome 10). The IBM2n genetic map has been anchored to the publicly available maize genomic sequence data by The Institute for Genomic Research (TIGR; provided online by TIGR). As of May 2005, $n=2,690$ unique genomic sequence accessions had been anchored to markers mapped on this genetic map, allowing us to integrate this sample of the total maize genes with the dQTL data. It was assumed that this was a representative, random sample of all maize genes. Regression of dQTL number on gene number per chromosome showed that much of the variance in dQTL number (73\%) could be attributed to gene number (Fig. 2). Inspection of the consensus map revealed an apparent clustering of dQTL for some diseases or groups of related diseases (e.g., viruses) and for all diseases taken together. The pericentric regions of several chromosomes were associated with clusters of co-localizing dQTL. Many telomeric regions were associated with very few or no dQTL.

The coverage of the majority of the maize genome with reported dQTL at least in part reflects the low precision and accuracy of QTL mapping (35), but could also be partly attributable to the great number of genes involved in the host-pathogen

\section{Chromosome 3}

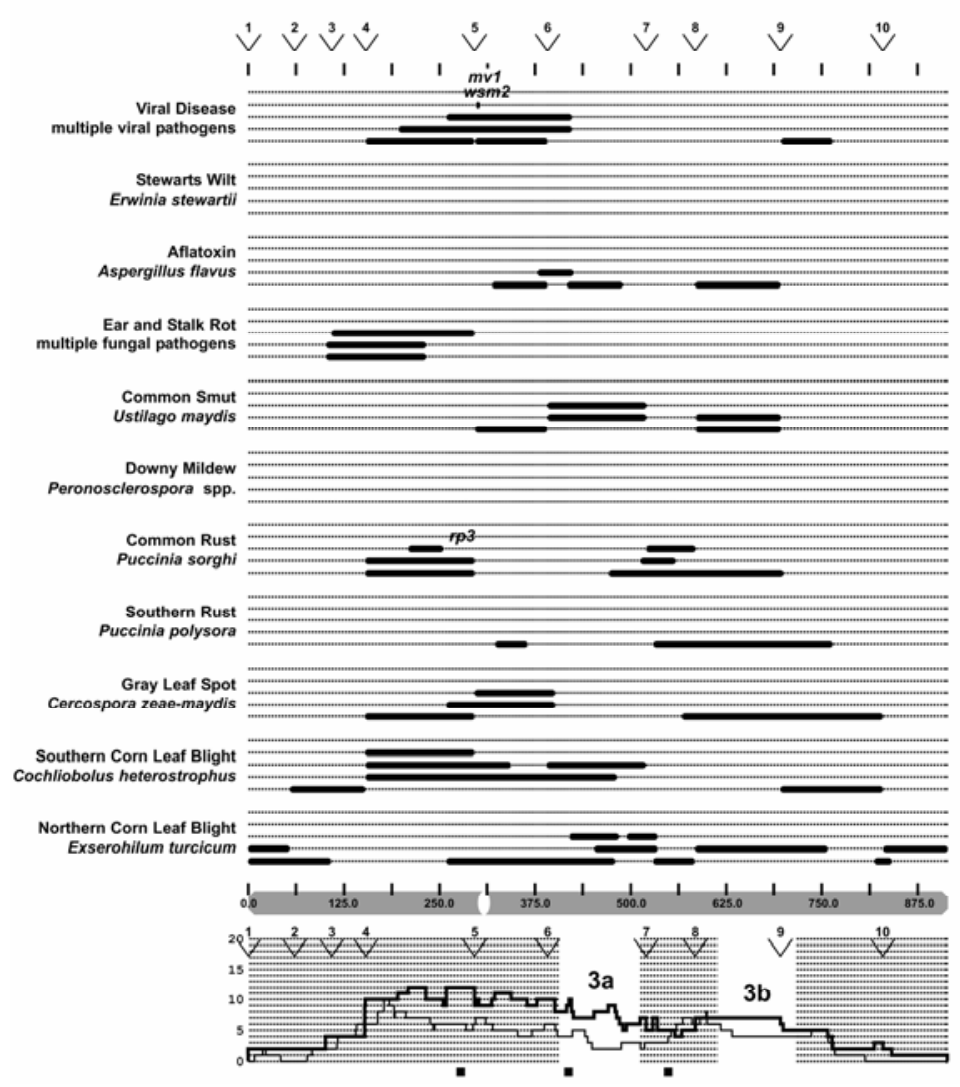

\section{Chromosome 4}

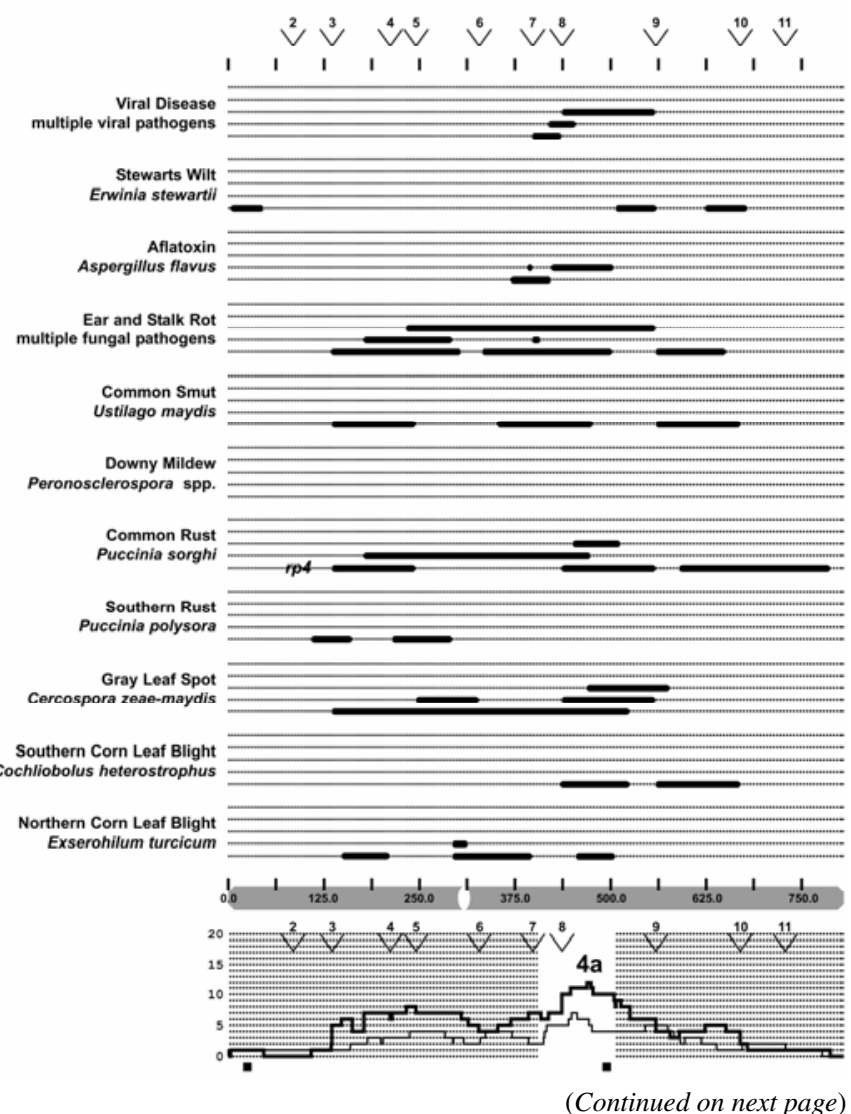

Fig. 1. (Continued from preceding page). 
interaction. For instance, thousands of genes are found to be differentially expressed in microarray analyses of the plant defense response (29). In addition, disease resistance may be conditioned by genes affecting growth and development, as discussed below.

Clustering of quantitative trait loci. Since McMullen and Simcox (51) noted the apparent clustering of disease and insect resistance loci in maize, many more dQTL have been declared. To test the significance of the apparent dQTL clustering in this larger and more precisely synthesized body of data, we determined the probability that the observed distribution could occur by chance alone. The data were summarized in a way that would minimize the differential weighting of different dQTL based on variation in their apparent length. That is, if bins were much smaller than QTL, the analysis would be biased in favor of poorly resolved QTL (78). To avoid this bias, a new bin structure was constructed, corresponding to the average dQTL length in the data set. Each dQTL was assigned to these bins according to the following rule: if a dQTL had its midpoint in a bin, and/or if it covered an entire bin, it was scored to that bin. Disease QTL and a sample of all maize genes were assigned to 73 bins of approximately $107 \mathrm{cM}$ (the average dQTL length on the IBM2n map), which were designated alternative bins or "A-bins". Note that a single QTL could be counted more than once, if its confidence interval covered multiple bins. We also took into account the distribution of genes in the maize genome, since dQTL numbers and gene numbers were significantly correlated (gene density explained $29 \%$ of the total $A$-bin dQTL distribution; $P=9.0 \times 10^{-7}$ ). Finally, the data set could be evaluated as a frequency distribution, to determine whether the distribution of dQTL number per bin deviated significantly from an expected random distribution accounting for gene density.

The observed dQTL data were evaluated in relation to an expected random multinomial distribution under the following assumptions: (i) the sample of mapped maize gene sequences available in the TIGR database was a representative, random sample of all maize genes; (ii) each $A$-bin had a probability of containing a QTL equal to the proportion of total genes in that bin; (iii) each of the trials that assigned a QTL to an $A$-bin was comparable; and (iv) each QTL was independent. Under the second assumption, for example, the probability of a QTL to be located in A-bin 1.05 was $2.2 \%$ (it contained 60 of the 2,690 identified gene sequences), and would therefore be expected to have eight QTL $(0.022 \times$ total number of observed QTL assigned to $A$-bins, $n=$ $344)$. The result indicated that clustering was significant. That is, the hypothesis that the dQTL data were randomly distributed, having accounted for gene density, could be rejected $(P=4.5 \times$ $\left.10^{-5}\right)$. We also measured the coefficient of dispersion $(\mathrm{CD}=$ the ratio of the variance to the mean), another measure of clustering. $\mathrm{A} C D$ value of greater than one would signify clustering. The $\mathrm{CD}$ for the number of dQTL per $A$-bin was equal to 2.6, indicating a significant degree of clustering.

For each $A$-bin, we also determined the ratio of the number of observed dQTL to the number expected based on gene density. These ratios ranged from 0.0 to 3.6 , with a mean of 1.0. A-bins with ratios of greater than $1.0(n=32,44 \%$ of the $A$-bins $)$ had
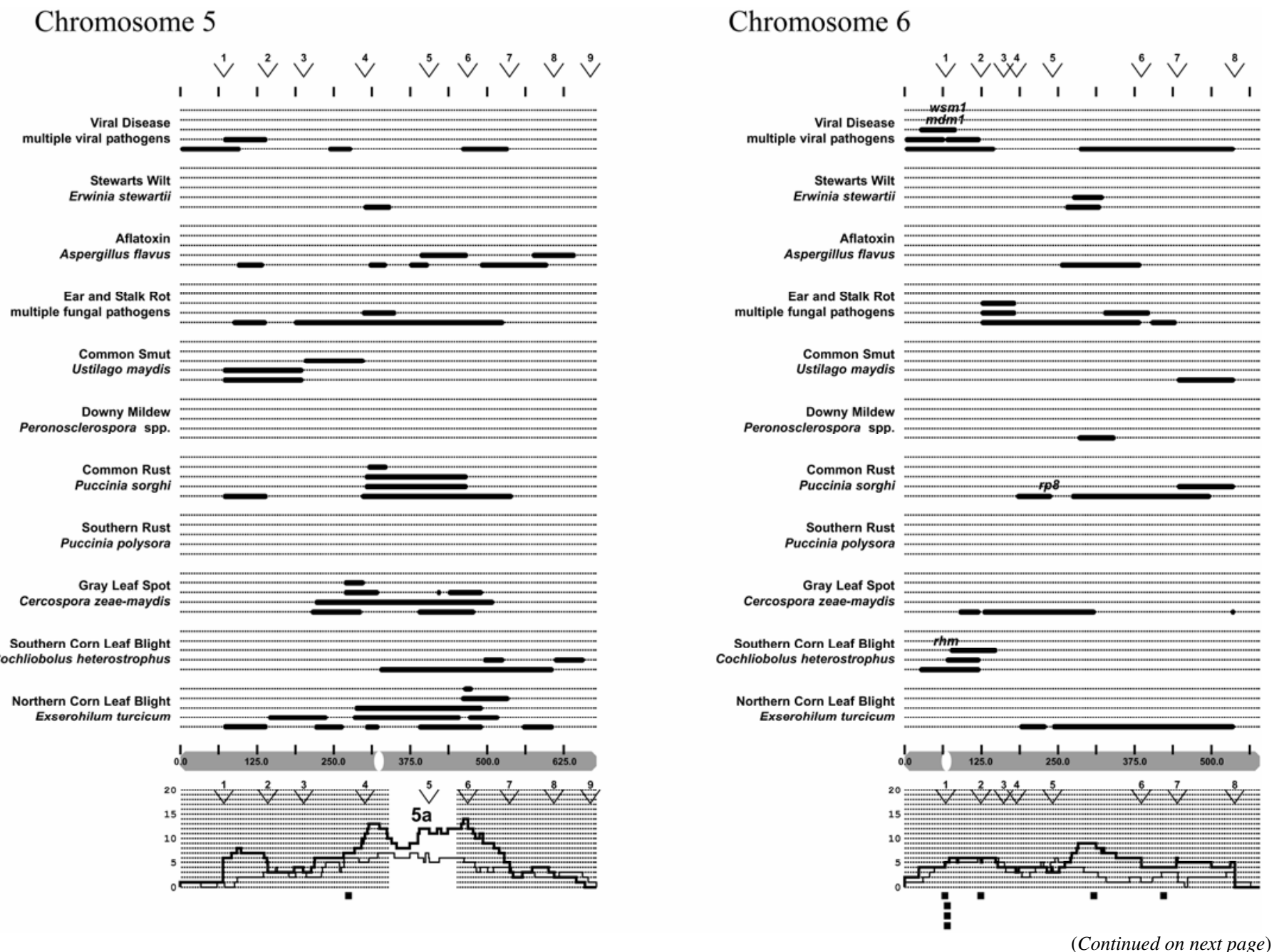

Fig. 1. (Continued from preceding page). 
more observed QTL than would be expected from the genome average when considering gene density. Eight dQTL clusters were identified with at least twice the number of dQTL expected (Fig. 1). There were two such clusters on chromosomes 1 and 3 , and one each on chromosomes $2,4,5$, and 10 . These regions did not always coincide with those $A$-bins containing the largest number of observed dQTL. Future analysis should be focused on chromosomal regions with high per-gene dQTL densities, in addition to those regions with high per-bin dQTL densities.

A relatively small number of major genes have been mapped in maize, considering its importance as both a crop and as a model system. This may reflect the relatively low importance of major genes in maize in controlling disease in the field. Of the 17 major genes described in this review, some correspondences with dQTL for the same diseases were evident (Fig. 1). Co-localization of the major virus resistance genes (Msv1, Mv1,Wsm1, Wsm2, Wsm3, and $M d m 1$ ) and viral dQTL were evident. Many of these viral dQTL, however, had very large effects, explaining between 25 to $50 \%$ of total variation, and might be better described as major genes $(38,42,60,76)$. A recessive gene conferring resistance to southern corn leaf blight (SCLB), rhm, co-localized with SCLB dQTL on chromosome 6. Rp3, a common rust resistance gene, colocalized with common rust dQTL on chromosome 3. Two northern corn leaf blight (NCLB) major genes, Ht2 and Htn 1, co-localized with NCLB dQTL on chromosome 8 . Though small, this sample set certainly supports conjectures made in other systems (26) that in some cases genes for quantitative resistance may be alleles of major resistance genes.

It is possible that the apparent clustering of dQTL may reflect, in part, a nonrandom distribution of resistance loci, for instance in co-adapted gene complexes or clusters of related genes involved in plant defense. Alternatively, the apparent clustering could be due, in whole or in part, to genes exhibiting pleiotropy for multiple diseases (or multiple disease resistance). In interpreting the clustering of dQTL, some caveats should be noted. Clustering of resistance loci may also be due, at least to some extent, to biases in QTL analysis $(35,54)$, to allelic re-sampling, and/or to a nonrandom distribution of all maize genes. We cannot quantify the extent to which apparent QTL clustering resulted from artifacts. While we took effort to remove redundant QTL, we were only able to identify putatively redundant QTL when alleles from the same cultivar were associated with resistance at a given locus. Thus, cultivar names were a surrogate for identity by descent, which may underestimate the true extent of allelic re-sampling. Clustering was still observed after accounting for the distribution of genes in the maize genome.

Multiple disease resistance. Many common chromosomal segments were associated with resistance to multiple diseases on the dQTL consensus map. Every maize chromosome had co-localizing dQTL for at least two different diseases. McMullen and Simcox (51) pointed out tight clusters of resistance factors in bins 3.04 and 6.01. In the present study, these chromosomal regions were again associated with clusters of resistance factors. Bins 3.04 to 3.05 were associated with resistance to 6 of the 11 diseases and/or disease groups shown, while bin 6.01 was primarily associated with viral and SCLB resistance. Several of the loci within these bins explained large proportions of the phenotypic variance (data not shown), while in some cases these were clearly qualitative resistance loci. While the present analysis confirmed the high number of dQTL per bin for these two bins, neither

\section{Chromosome 7}

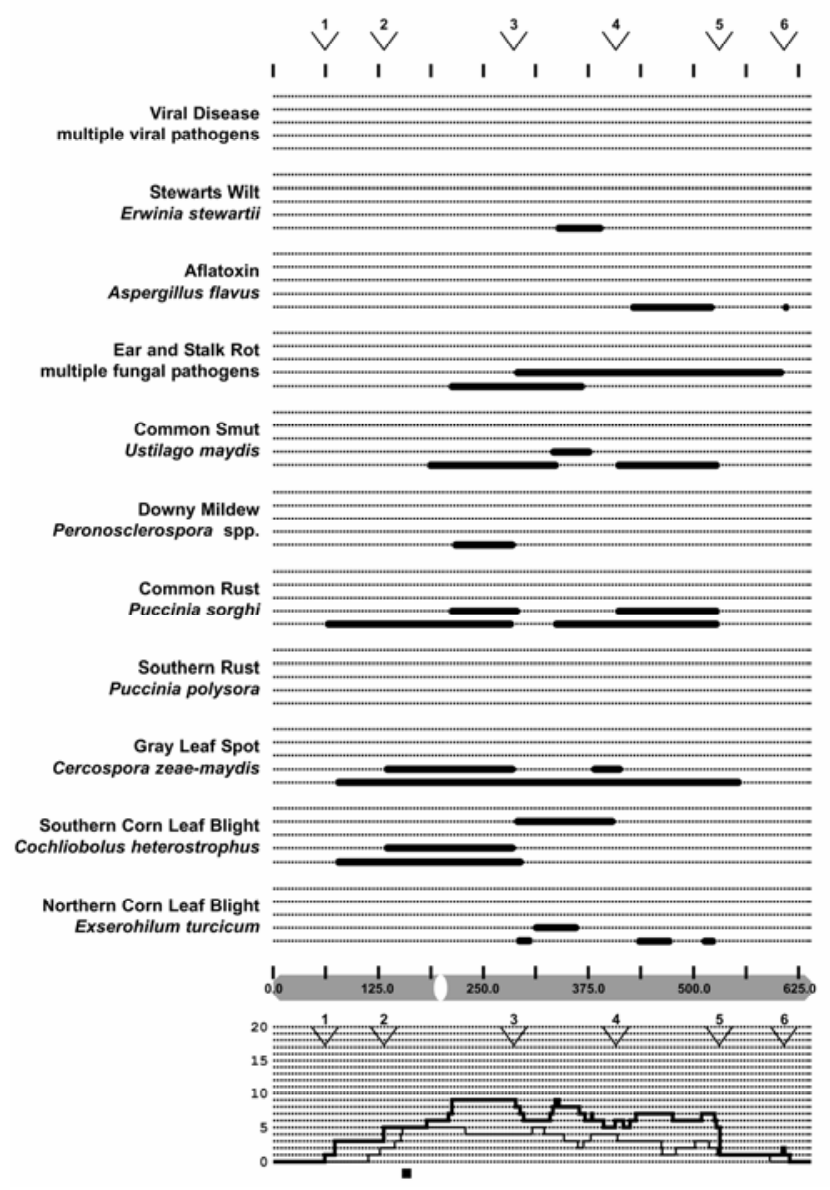

\section{Chromosome 8}

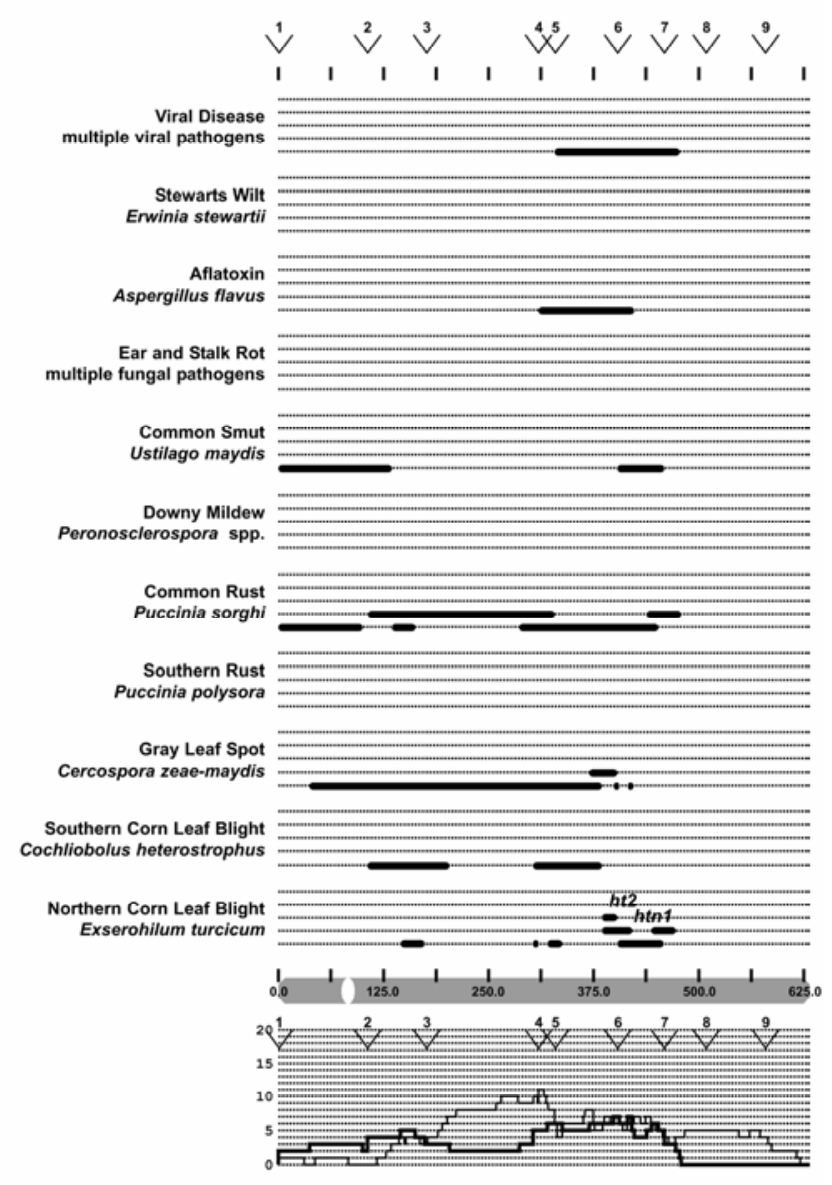

(Continued on next page)

Fig. 1. (Continued from preceding page). 
region contained more than twice the number of dQTL than expected based on gene density.

Other genomic segments were notable for a relatively tight linkage or correspondence for quantitative resistance loci, as well as for high dQTL per gene ratios. For example, part of cluster $2 \mathrm{a}$ $(\approx 315$ to $375 \mathrm{cM}$ of chromosome 2) (Fig. 1) was associated with QTL for 9 of the 11 diseases and/or disease groups shown, which was reflected in the sharp peak in the dQTL histogram in Figure 1. It should be noted here that these estimates of genetic distance pertain to the IBM2n map, which was derived from an intermated population of maize lines. The centimorgan values are larger, by a factor of approximately fourfold, than those that would have been obtained using an $\mathrm{F}_{2}$ population (44). Similarly, for part of cluster 4a $(\approx 450$ to $500 \mathrm{cM}$ on chromosome 4 , Fig. 1), QTL for eight different diseases co-localized. In fact, each chromosome had several independent dQTL clusters (peaks in the histograms), with some more dispersed than others. Often these clusters were composed of dQTL for different diseases identified in different mapping populations (Table 1; Fig. 1).

Some studies have directly evaluated the extent of overlapping QTL for multiple diseases identified in the same biparental mapping population. In a maize mapping population derived from a cross between a highland inbred and lowland inbred, Jiang et al. (36) found no positional correspondences between the few QTL identified for NCLB, SCLB, and common rust. Considering only the QTL detected in both years of their study of the cross IL731a $\times$ W6786, Brown et al. (5) suggested that QTL for NCLB, common rust, and Stewart's wilt were unlinked. In contrast, Kerns et al. (41) found 21 QTL and 14 QTL associated with resistance to common rust and smut, respectively, nine of which co-localized. Welz et al. (77) evaluated the genetic relationships of resistance to NCLB, head smut, common smut, and common rust for the same population. They found strong evidence for the association of loci for resistance to NCLB, head smut, and common rust, but not common smut. Genetic dissection of chromosomal regions putatively associated with multiple disease resistance will allow remaining questions about linkage and pleiotropy to be addressed.

Comparisons of QTL for disease and maturity in maize. Genes identified in dQTL studies might affect disease either directly or indirectly. Those affecting disease indirectly, such as through effects on plant growth or development, might affect other agronomically important traits, such as the length of time it takes for the plant to mature. There is reason, in fact, to suspect a relationship between plant resistance and maturity. Some diseases, especially those caused by necrotrophic pathogens (i.e., those that kill host cells and derive nutrition from them), such as NCLB, SCLB, gray leaf spot, and anthracnose leaf blight, are most severe on senescing leaf tissue after anthesis (66). When a diverse 300-line panel of maize germplasm was evaluated for both SCLB resistance and flowering time, $23 \%$ of the variance for resistance was explained by variation in flowering time (P. J. Balint-Kurti, unpublished data). On the other hand, several mapping studies have examined both maturity-related and diseaserelated traits in the same populations and none showed a strong correlation between the two traits $(9,11,36,69)$, although some colocalization of dQTL and maturity-related QTL (mQTL) and/or significant correlation between disease resistance and time to anthesis was observed in some studies.

\section{Chromosome 9}

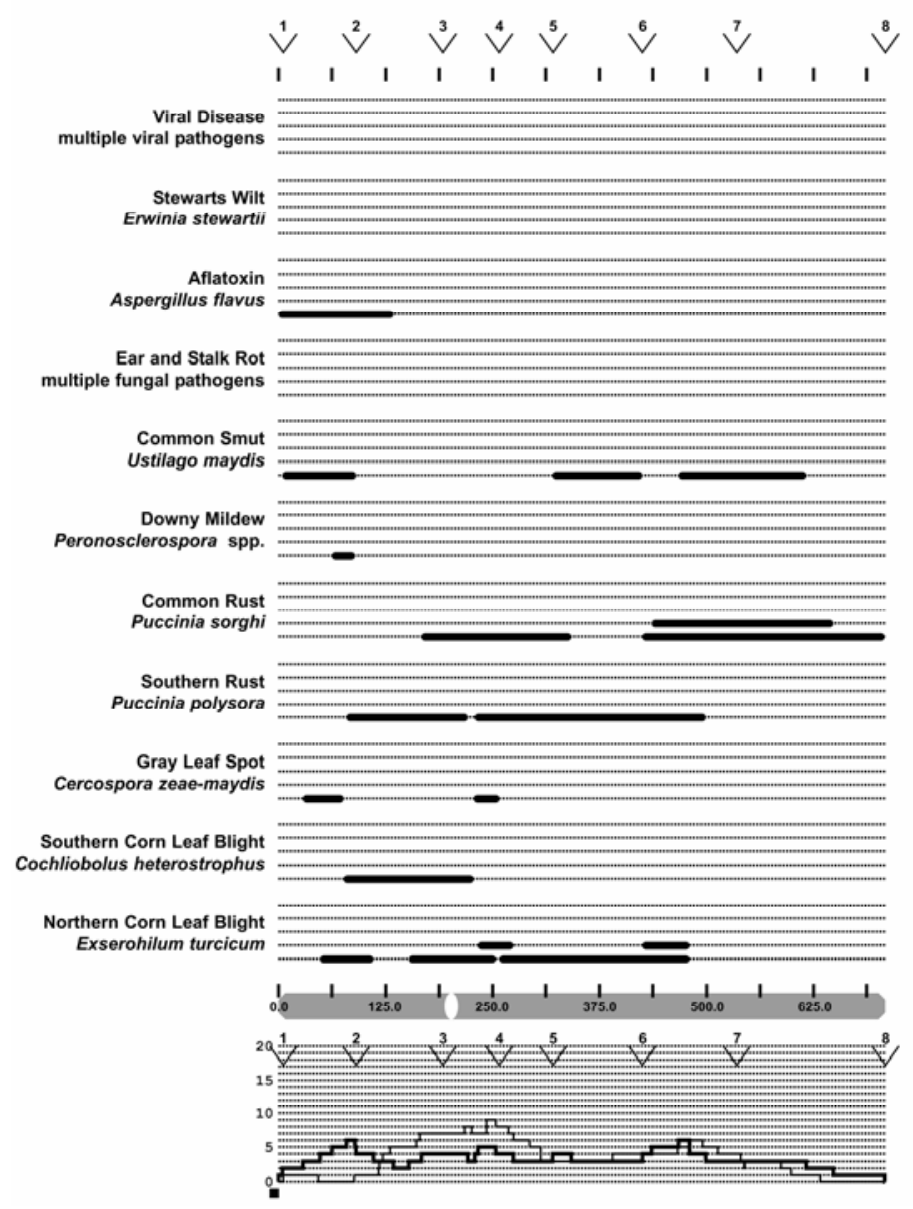

\section{Chromosome 10}

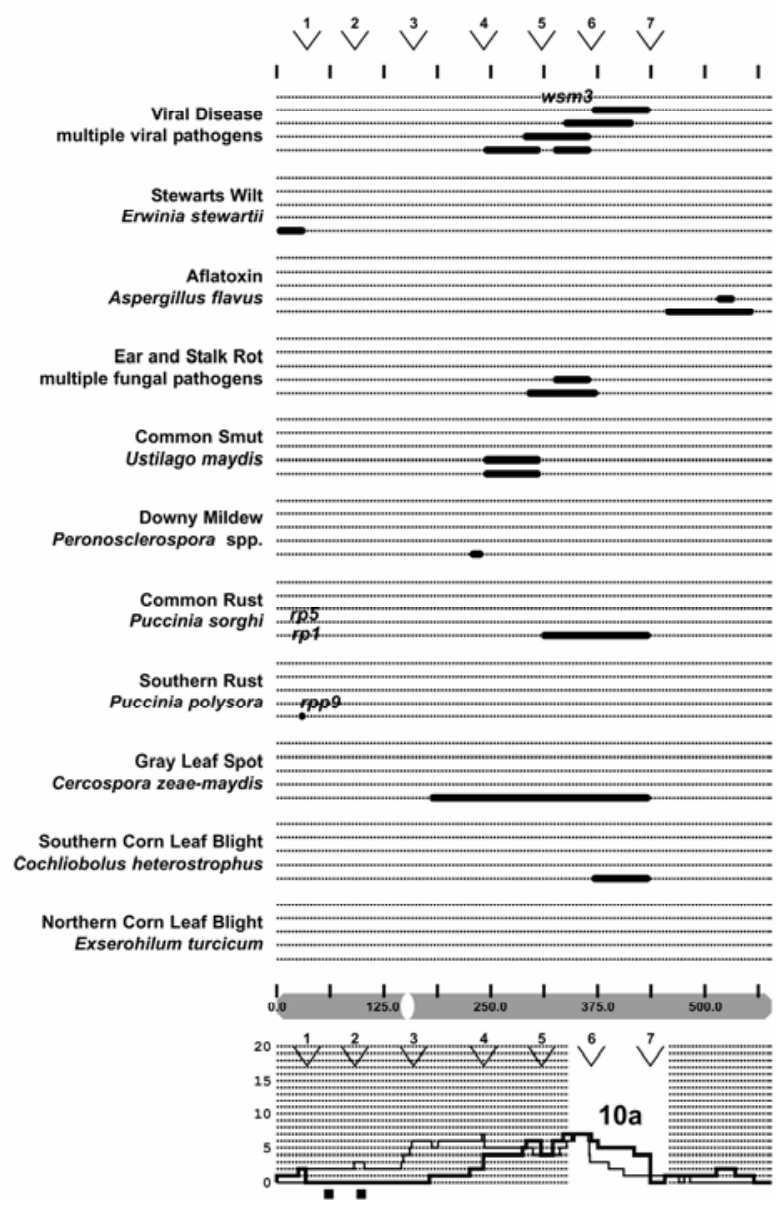

Fig. 1. (Continued from preceding page). 
A recent study reported on a meta-analysis of $\mathrm{mQTL}$ in maize (13). We examined the relationship of chromosomal positions of reported mQTL with positions of dQTL. The data synthesized by Chardon et al. (13), relating to flowering time, plant height, and leaf number (maturity-related traits), were anchored onto the IBM2n map using the homothetic function (described previously). Chardon et al. (13), however, did not report information that would be needed to identify potentially redundant mQTL in the manner used for the dQTL summary, so an alternative approach was used: overlapping mQTL from the same publication were considered potentially redundant and were thus counted only once. Our analysis showed that there was a significant $(P=$ 0.00057) association of QTL for the two phenotypes after accounting for gene density, with $16 \%$ of the variation in chromosomal position of dQTL explicable by the positions of mQTL. Recall that gene density explains, in part, the co-localization of QTL (see Figure 2 and the section on "clustering of quantitative trait loci"). It was therefore expected that any relationship between the two separate QTL data sets of dQTL and mQTL would, in part, be explicable by gene density. To remove the affect of gene density, regressions were performed using the per- $A$-bin ratios of dQTL/ gene number (dependent variable) and $\mathrm{mQTL} /$ gene number (independent variable). When dQTL for each of the necrotrophic leaf diseases were used in the regression analysis, significant variance was explained by mQTL for SCLB $\left(R^{2}=0.11, P=0045\right)$ but not for NCLB or gray leaf spot.

We graphed the number of dQTL and mQTL along each chromosome (Fig. 1). While some peaks coincided (e.g., at bin 3.04), there were several peaks in dQTL number that did not correspond to peaks of mQTL frequency (e.g., at bin 7.03). This combined summary will facilitate the identification of chromosomal regions more likely to be directly involved in reducing disease susceptibility.

Directions for future research. The consensus dQTL map presented here has implications for maize breeding. For instance, the QTL for viral resistance are relatively tightly clustered, suggesting that a limited number of loci are involved in conditioning resistance. Thus, pedigree breeding could be most appropriate for transferring virus resistance and marker-assisted selection may be

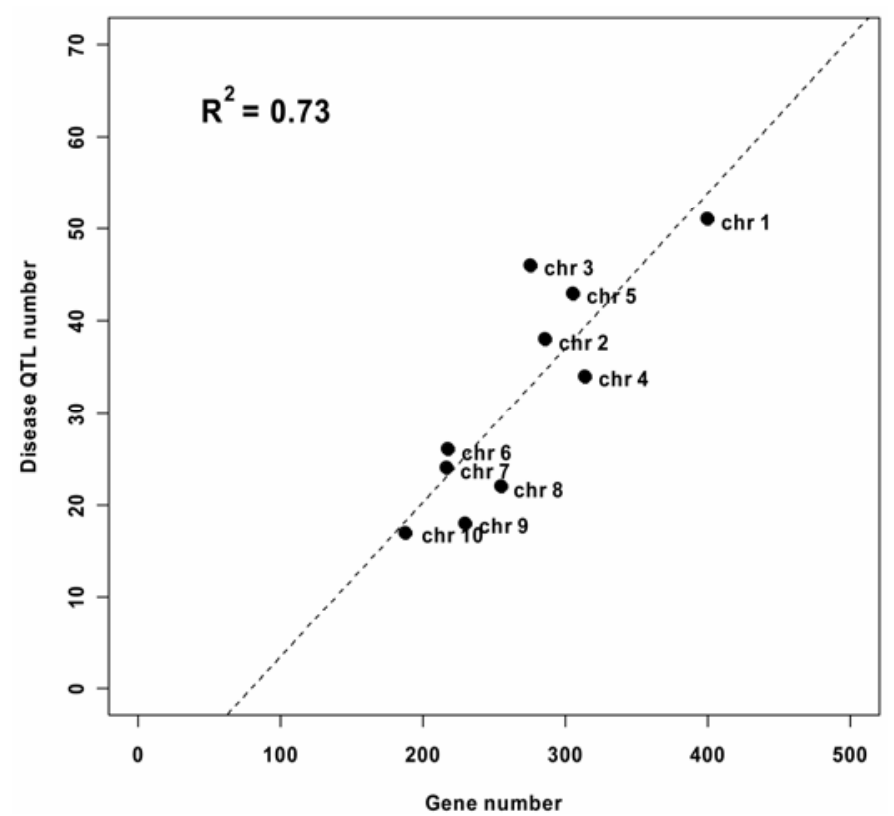

Fig. 2. Relationship between the number of disease quantitative trait loci and genes per chromosome, for the 10 chromosomes of maize. Gene number was calculated from the 2,690 unique sequence accessions that had been related to markers mapped to the IBM2n genetic map by The Institute for Genomic Research (TIGR) (provided online by TIGR), as of May 2005. feasible. For NCLB, the reported QTL distribution is much more diffuse. To improve NCLB resistance, it might be appropriate to bring together diverse sources of resistance alleles. Recurrent selection might be the most effective way to do this. Indeed, recurrent selection has produced dramatic increases in NCLB resistance (12).

On the consensus map, dQTL nearly or completely covered each of the chromosomes. This may be due, in part, to a multiplicity of genes conditioning resistance. However, the near-complete genome coverage must be largely due to the low precision of QTL localization. Low precision resulted in very large dQTL size estimates: the reported dQTL had an average size of $107 \mathrm{cM}$ on the IBM2n map, which would correspond to $\approx 28 \mathrm{cM}$ on an $\mathrm{F}_{2}$ map (44). QTL interval estimates can, in principle, be refined by meta-analysis $(13,30)$. To reach the sample size sufficient for meta-analysis of these data, QTL for multiple diseases would have to be used. This would require the questionable assumption that the multiple diseases were conditioned by the same genes.

There is a clear need for further genetic dissection of the QTL to more precisely localize the genes involved. The process of genetic dissection of QTL will involve the production and refinement of near-isogenic lines (NILs). Work is on-going in our laboratories to develop NILs for dQTL. The availability of NILs will make it possible to characterize the QTL, and will eventually allow the genes conditioning the QTL to be isolated. Ideally, a set of NILs will contain a set of alleles at a range of QTL, and also a series of alleles at selected loci of interest. As NILs are developed and refined through successive generations of backcrossing, the set of genes carried on the introgressed chromosomal segment is serially reduced and the questions regarding the phenotypic effects of certain loci can be refined to pertain to a defined set of genes, and eventually to an individual gene (literature citation 65 provides a review of map-based cloning of QTL). Genes underlying QTL have been cloned in plants by this approach (21).

The availability of NILs will allow many unresolved questions regarding quantitative disease resistance to be addressed. One such question relates to the issue of multiple disease resistance: do certain loci condition resistance to multiple pathogens? Another long-standing issue is the extent to which QTL are isolatespecific or nonspecific in their effects. It will eventually be possible to determine the precise effect of each allele on pathogen development in relation to a range of isolates, and on the expression of genes in both the host and pathogen under different environmental conditions. The maize genome carries a number of duplications that have arisen at different times in the evolutionary history of Zea mays (25). As QTL locations are refined and maize genome duplications are more thoroughly characterized, it will be of interest to examine how QTL and their specificities have evolved after duplication events.

\section{ACKNOWLEDGMENTS}

We thank members of the Institute for Genomic Diversity at Cornell University, particularly S. C. Murray and P. J. Brown, for their advice and discussions; and A. Charcosset for providing the positional data of maturity-related maize QTL. This study was supported by grants from The Rockefeller Foundation and The Generation Challenge Program.

\section{LITERATURE CITED}

1. Agrama, H. A., Moussa, M. E., Naser, M. E., Tarek, M. A., and Ibrahim, A. H. 1999. Mapping of QTL for downy mildew resistance in maize. Theor. Appl. Genet. 99:519-523.

2. Balint-Kurti, P. J., and Carson, M. L. 2006. Quantitative trait loci for resistance to southern leaf blight in juvenile maize. Phytopathology (In press.)

3. Bentolila, S., Guitton, C., Bouvet, N., Sailland, A., Nykaza, S., and Freyssinet, G. 1991. Identification of an RFLP marker tightly linked to the Ht1 gene in maize. Theor. Appl. Genet. 82:393-398.

4. Brooks, T. D., Williams, W. P., Windham, G. L., Willcox, M. C., and Abbas, H. K. 2005. Quantitative trait loci contributing resistance to aflatoxin accumulation in the maize inbred Mp313E. Crop Sci. 45:171-174. 
5. Brown, A. F., Juvik, J. A., and Pataky, J. K. 2001. Quantitative trait loci in sweet corn associated with partial resistance to Stewart's wilt, northern corn leaf blight, and common rust. Phytopathology 91:293-300.

6. Brunelli, K. R., Silva, H. P., and Aranha-Camargo, L. E. 2002. Mapeamento de genes de resistencia quantitativa a Puccinia polysora em milho. Fitopatol. Bras. 27:134-140.

7. Brunner, S., Fengler, K., Morgante, M., Tingey, S., and Rafalski, A. 2005. Evolution of DNA sequence nonhomologies among maize inbreds. Plant Cell 17:343-360.

8. Bubeck, D. M. 1992. Molecular and biometric evaluation of gray leaf spot and southern corn leaf blight resistance in maize. Ph.D. thesis. North Carolina State University, Raleigh.

9. Bubeck, D. M., Goodman, M. M., Beavis, W. D., and Grant, D. 1993. Quantitative trait loci controlling resistance to gray leaf spot in maize. Crop Sci. 33:838-847.

10. Busboom, K. N., and White, D. G. 2004. Inheritance of resistance to aflatoxin production and Aspergillus ear rot of corn from the cross of inbreds B73 and Oh516. Phytopathology 94:1107-1115.

11. Carson, M. L., Stuber, C. W., and Senior, M. L. 2004. Identification and mapping of quantitative trait loci conditioning resistance to southern leaf blight of maize caused by Cochliobolus heterostrophus race 0. Phytopathology 94:862-867.

12. Ceballos, H., Deutsch, J. A., and Gutierrez, H. 1991. Recurrent selection for resistance to Exserohilum turcicum in eight subtropical maize populations. Crop Sci. 31:964-971.

13. Chardon, F., Virlon, B., Moreau, L., Falque, M., Joets, J., Decousset, L., Murigneux, A., and Charcosset, A. 2004. Genetic architecture of flowering time in maize as inferred from quantitative trait loci meta-analysis and synteny conservation with the rice genome. Genetics 168:2169-2185.

14. Clements, M. J., Dudley, J. W., and White, D. G. 2000. Quantitative trait loci associated with resistance to gray leaf spot of corn. Phytopathology 90:1018-1025

15. Coe, E. H., Neuffer, M. G., and Hoisington, D. A. 1988. The Genetics of Corn. Pages 81-258 in: Corn and Corn Improvement. G. F. Sprague and J. W. Dudley, eds. Crop Science Society of America, Madison, WI.

16. Collins, N. C., Webb, C. A., Seah, S., Ellis, J. G., Hulbert, S. H., and Pryor, A. 1998. The isolation and mapping of disease resistance gene analogs in maize. Mol. Plant-Microbe Interact. 11:968-978.

17. Darvasi, A., and Soller, M. 1997. A simple method to calculate resolving power and confidence interval of QTL map location. Behav. Genet. 27:125-132.

18. Davis, G. L., McMullen, M. D., Baysdorfer, C., Musket, T., Grant, D., Staebell, M., Xu, G., Polacco, M., Koster, L., Melia-Hancock, S., Houchins, K., Chao, S., and Coe, E. H., Jr. 1999. A maize map standard with sequenced core markers, grass genome reference points and 932 expressed sequence tagged sites (ESTs) in a 1736-locus map. Genetics 152:1137-1172.

19. Delaney, D. E., Webb, C. A., and Hulbert, S. H. 1998. A novel rust resistance gene in maize showing overdominance. Mol. Plant-Microbe Interact. 11:242-245.

20. Dingerdissen, A. L., Geiger, H. H., Lee, M., Schechert, A., and Welz, H. G. 1996. Interval mapping of genes for quantitative resistance of maize to Setosphaeria turcica, cause of northern leaf blight, in a tropical environment. Mol. Breed. 2:143-156.

21. Frary, A., Nesbitt, T. C., Frary, A., Grandillo, S., van der Knaap, E., Cong, B., Liu, J., Meller, J., Elber, R., Alpert, K. B., and Tanksley, S. D. 2000. fw2.2: A quantitative trait locus key to the evolution of tomato fruit size. Science 289:85-88.

22. Freymark, P. J., Lee, M., Woodman, W. L., and Martinson, C. A. 1993. Quantitative and qualitative trait loci affecting host-plant response to Exserohilum turcicum in maize (Zea mays L.). Theor. Appl. Genet. 87:537-544.

23. Fu, H., and Dooner, H. K. 2002. Intraspecific violation of genetic colinearity and its implications in maize. Proc. Natl. Acad. Sci. USA 99:9573-9578.

24. Gardiner, J. M., Coe, E. H., Melia-Hancock, S., Hoisington, D. A., and Chao, S. 1993. Development of a core RFLP map in maize using an immortalized $\mathrm{F}_{2}$ population. Genetics 134:917-930.

25. Gaut, B. S. 2001. Patterns of chromosomal duplication in maize and their implications for comparative maps of the grasses. Genome Res. 11:55-66.

26. Gebhardt, C., and Valkonen, J. P. T. 2001. Organization of genes controlling disease resistance in the potato genome. Annu. Rev. Phytopathol. 39:79-102.

27. George, M. L. C., Prasanna, B. M., Rathore, R. S., Setty, T. A. S., Kasim, F., Azrai, M., Vasal, S., Balla, O., Hautea, D., Canama, A., Regalado, E., Vargas, M., Khairallah, M., Jeffers, D., and Hoisington, D. 2003. Identification of QTLs conferring resistance to downy mildews of maize in Asia. Theor. Appl. Genet. 107:544-551.

28. Glazebrook, J. 2001. Genes controlling expression of defense responses in Arabidopsis-2001 status. Curr. Opin. Plant Biol. 4:301-308.
29. Glazebrook, J., Chen, W., Estes, B., Chang, H. S., Nawrath, C., Metraux, J. P., Zhu, T., and Katagiri, F. 2003. Topology of the network integrating salicylate and jasmonate signal transduction derived from global expression phenotyping. Plant J. 34:217-228.

30. Goffinet, B., and Gerber, S. 2000. Quantitative trait loci: A meta-analysis. Genetics 155:463-473.

31. Gordon, S. G., Bartsch, M., Matthies, I., Gevers, H. O., Lipps, P. E., and Pratt, R. C. 2004. Linkage of molecular markers to Cercospora zeaemaydis resistance in maize. Crop Sci. 44:628-636.

32. Hammond-Kosack, K. E., and Parker, J. E. 2003. Deciphering plantpathogen communication: Fresh perspectives for molecular resistance breeding. Curr. Opin. Biotechnol. 14:177-193.

33. Holland, J. B., Uhr, D. V., Jeffers, D., and Goodman, M. M. 1998. Inheritance of resistance to southern corn rust in tropical-by-corn-belt maize populations. Theor. Appl. Genet. 96:232-241.

34. Huang, L. J., Xiang, D. Q., Yang, J. P., and Dai, J. R. 2002. Construction the RFLP linkage map and location the NCLB QTL of maize. Acta Genet. Sin. 29:1100-1104.

35. Hyne, V., Kearsey, M. J., Pike, D. J., and Snape, J. W. 1995. QTL analysis: Unreliability and bias in estimation procedures. Mol. Breed. $1: 273-282$

36. Jiang, J. C., Edmeades, G. O., Armstead, I., Lafitte, H. R., Hayward, M. D., and Hoisington, D. 1999. Genetic analysis of adaptation differences between highland and lowland tropical maize using molecular markers. Theor. Appl. Genet. 99:1106-1119.

37. Johal, G. S., and Briggs, S. P. 1990. Placement of $h m l$ on the Pioneer RFLP map. Maize Genet. Coop. Newsl. 64:37.

38. Jones, M. W., Redinbaugh, M. G., Anderson, R. J., and Louie, R. 2004. Identification of quantitative trait loci controlling resistance to maize chlorotic dwarf virus. Theor. Appl. Genet. 110:48-57.

39. Jung, M., Weldekidan, T., Schaff, D., Paterson, A., Tingey, S., and Hawk, J. 1994. Generation-means analysis and quantitative trait locus mapping of anthracnose stalk rot genes in maize. Theor. Appl. Genet. 89:413-418.

40. Kearsey, M. J., and Farquhar, A. G. L. 1998. QTL analysis in plants; Where are we now? Heredity 80:137-142.

41. Kerns, M. R., Dudley, J. W., and Rufener, G. K. 1999. QTL for resistance to common rust and smut in maize. Maydica 44:37-45.

42. Kyetere, D., Ming, R., McMullen, M., Pratt, R., Brewbaker, J., Musket, T., Pixley, K., and Moon, H. 1995. Monogenic tolerance to maize streak virus maps to the short arm of chromosome 1. Maize Genet. Coop. Newsl. 69:136-137.

43. Kyetere, D. T., Ming, R., McMullen, M. D., Pratt, R. C., Brewbaker, J., and Musket, T. 1999. Genetic analysis of tolerance to maize streak virus in maize. Genome 42:20-26.

44. Lee, M., Sharopova, N., Beavis, W. D., Grant, D., Katt, M., Blair, D., and Hallauer, A. 2002. Expanding the genetic map of maize with the intermated B73 × Mo17 (IBM) population. Plant Mol. Biol. 48:453-461.

45. Lehmensiek, A., Esterhuizen, A. M., Van-Staden, D., Nelson, S. W., and Retief, A. E. 2001. Genetic mapping of gray leaf spot (GLS) resistance genes in maize. Theor. Appl. Genet. 103:797-803.

46. Lindhout, P. 2002. The perspectives of polygenic resistance in breeding for durable disease resistance. Euphytica 124:217-226.

47. Lübberstedt, T., Klein, D., and Melchinger, A. E. 1998. Comparative quantitative trait loci mapping of partial resistance to Puccinia sorghi across four populations of European flint maize. Phytopathology 88:13241329.

48. Lübberstedt, T., Klein, D., and Melchinger, A. E. 1998. Comparative QTL mapping of resistance to Ustilago maydis across four populations of European flint-maize. Theor. Appl. Genet. 97:1321-1330.

49. Marçon, A., Kaeppler, S. M., Jensen, S. G., Senior, L., and Stuber, C. 1999. Loci controlling resistance to high plains virus and wheat streak mosaic virus in a B73 $\times$ Mo17 population of maize. Crop Sci. 39:11711177.

50. McMullen, M. D., Jones, M. W., Simcox, K. D., and Louie, R. 1994. Three genetic loci control resistance to wheat streak mosaic virus in the maize inbred Pa405. Mol. Plant-Microbe Interact. 7:708-712.

51. McMullen, M. D., and Simcox, K. D. 1995. Genomic organization of disease and insect resistance genes in maize. Mol. Plant-Microbe Interact. 8:811-815

52. Ming, R., Brewbaker, J. L., Pratt, R. C., Musket, T. A., and McMullen, M. D. 1997. Molecular mapping of a major gene conferring resistance to maize mosaic virus. Theor. Appl. Genet. 95:271-275.

53. Multani, D. S., Meeley, R. B., Paterson, A. H., Gray, J., Briggs, S. P., and Johal, G. S. 1998. Plant-pathogen microevolution: Molecular basis for the origin of a fungal disease in maize. Proc. Natl. Acad. Sci. USA 95:168691.

54. Noor, M. A. F., Cunningham, A. L., and Larkin, J. C. 2001. Consequences of recombination rate variation on quantitative trait locus mapping studies: Simulations based on the Drosophila melanogaster genome. Genetics 159:581-588. 
55. Parlevliet, J. E. 2002. Durability of resistance against fungal, bacterial and viral pathogens; present situation. Euphytica 124:147-156.

56. Paterson, A. H., Lander, E. S., Hewitt, J. D., Peterson, S., Lincoln, S. E., and Tanksley, S. D. 1988. Resolution of quantitative traits into Mendelian factors by using a complete linkage map of restriction fragment length polymorphisms. Nature 335:721-726.

57. Paul, C., Naidoo, G., Forbes, A., Mikkilineni, V., White, D., and Rocheford, T. 2003. Quantitative trait loci for low aflatoxin production in two related maize populations. Theor. Appl. Genet. 107:263-270.

58. Pe, M. E., Gianfranceschi, L., Taramino, G., Tarchini, R., Angelini, P., Dani, M., and Binelli, G. 1993. Mapping quantitative trait loci (QTLs) for resistance to Gibberella zeae infection in maize. Mol. Gen. Genet. 241:11-16.

59. Pérez-Brito, D., Jeffers, D., Gonzales-De-León, D., Cortes-Cruz, M., Velásquez-Cardelas, G., Azpiroz-Rivero, S., and Srinivasan, G. 2001. Cartografia de QTL de la resistencia a la pudrición de la mazorca (Fusarium moniliforme) en maiz de Valles Altos, México. Agrociencia 35:181-196.

60. Pernet, A., Hoisington, D., Dintinger, J., Jewell, D., Jiang, C., Khairallah, M., Letourmy, P., Marchand, J.-L., Glaszmann, J.-C., and González de León, D. 1999. Genetic mapping of maize streak virus resistance from the Mascarene source. II. Resistance in line CIRAD390 and stability across germplasm. Theor. Appl. Genet. 99:540-553.

61. Pernet, A., Hoisington, D., Franco, J., Isnard, M., Jewell, D., Jiang, C., Marchand, J.-L., Reynaud, B., Glaszmann, J.-C., and González de León, D. 1999. Genetic mapping of maize streak virus resistance from the Mascarene source. I. Resistance in line D211 and stability against different virus clones. Theor. Appl. Genet. 99:524-539.

62. Prioul, J. L., Quarrie, S., Causse, M., and De-Vienne, D. 1997. Dissecting complex physiological functions through the use of molecular quantitative genetics. J. Exp. Bot. 48:1151-1163.

63. Quint, M., Dussle, C. M., Melchinger, A. E., and Lübberstedt, T. 2003. Identification of genetically linked RGAs by BAC screening in maize and implications for gene cloning, mapping and MAS. Theor. Appl. Genet. 106:1171-1177.

64. Rathjen, J. P., and Moffett, P. 2003. Early signal transduction events in specific plant disease resistance. Curr. Opin. Plant Biol. 6:300-306.

65. Remington, D. L., and Purugganan, M. D. 2003. Candidate genes, quantitative trait loci, and functional trait evolution in plants. Int. J. Plant Sci. 164:S7-S20.

66. Rupe, J. C., Siegel, M. R., and Hartman, J. R. 1982. Influence of environment and plant maturity on gray leaf spot of corn Zea mays caused by Cercospora zeae-maydis. Phytopathology 72:1587-1591.

67. Saghai Maroof, M. A., Yue, Y. G., Xiang, Z. X., Stromberg, E. L., and Rufener, G. K. 1996. Identification of quantitative trait loci controlling resistance to gray leaf spot disease in maize. Theor. Appl. Genet. 93:539546.

68. Sanz-Alferez, S., Richter, T. E., Hulbert, S. H., and Bennetzen, J. L. 1995 The Rp3 disease resistance gene of maize: Mapping and characterization of introgressed alleles. Theor. Appl. Genet. 91:25-32.

69. Schechert, A. W., Welz, H. G., and Geiger, H. H. 1999. QTL for resistance to Setosphaeria turcica in tropical African maize. Crop Sci. 39:514-523.

70. Simcox, K. D., and Bennetzen, J. L. 1993. The use of molecular markers to study Setosphaeria turcica resistance in maize. Phytopathology 83:1326-1330.

71. Simcox, K. D., McMullen, M. D., and Louie, R. 1995. Co-segregation of the maize dwarf mosaic virus resistance gene, $M d m 1$, with the nucleolus organizer region in maize. Theor. Appl. Genet. 90:341-346.

72. Sudupak, M. A., Hong, K. S., and Hulbert, S. H. 1992. Recombination between Rp1-G and Rp5. Maize Genet. Coop. Newsl. 66:71-72.

73. Tanksley, S. D. 1993. Mapping polygenes. Annu. Rev. Genet. 27:205-233.

74. Welz, H. G., and Geiger, H. H. 2000. Genes for resistance to northern corn leaf blight in diverse maize populations. Plant Breed. 119:1-14.

75. Welz, H. G., Schechert, A. W., and Geiger, H. H. 1999. Dynamic gene action at QTLs for resistance to Setosphaeria turcica in maize. Theor. Appl. Genet. 98:1036-1045.

76. Welz, H. G., Schechert, A. W., Pernet, A., Pixley, K. V., and Geiger, H. H. 1998. A gene for resistance to the maize streak virus in the African CIMMYT maize inbred line CML202. Mol. Breed. 4:147-154.

77. Welz, H. G., Xia, X. C., Bassetti, P., Melchinger, A. E., and Lübberstedt, T. 1999. QTLs for resistance to Setosphaeria turcica in an early maturing Dent $\times$ Flint maize population. Theor Appl. Genet. 99:649-655

78. Wisser, R. J., Qi, S., Hulbert, S. H., Kresovich, S., and Nelson, R. J. 2005. Identification and characterization of regions of the rice genome associated with broad-spectrum, quantitative disease resistance. Genetics 169:2277-2293.

79. Xia, X., Melchinger, A. E., Kuntze, L., and Lübberstedt, T. 1999. Quantitative trait loci mapping of resistance to sugarcane mosaic virus in maize. Phytopathology 89:660-667.

80. Young, N. D. 1996. QTL mapping and quantitative disease resistance in plants. Annu. Rev. Phytopathol. 34:479-501.

81. Yuan, L., Dußle, C. M., Melchinger, A. E., Utz, H. F., and Lübberstedt, T. 2003. Clustering of QTL conferring SCMV resistance in maize. Maydica 48:55-62.

82. Zaitlin, D., Demars, S., and Ma, Y. 1993. Linkage of rhm, a recessive gene for resistance to southern corn leaf blight, to RFLP marker loci in maize (Zea mays) seedlings. Genome 36:555-564.

83. Zaitlin, D., Demars, S. J., and Gupta, M. 1992. Linkage of a second gene for NCLB resistance to molecular markers in maize. Maize Genet. Coop. Newsl. 66:69-70. 